American Journal of Immunology 7 (2): 17-23, 2011

ISSN 1553-619X

(C) 2011 Science Publications

\title{
Evaluation of Immunomodulatory Effect: Selection of the Correct Targets for Immunostimulation Study
}

\author{
${ }^{1}$ Swee Keong Yeap, ${ }^{2}$ Mashitoh Binti Abd Rahman, \\ ${ }^{2}$ Noorjahan Banu Alitheen, ${ }^{2}$ Wan Yong Ho, \\ ${ }^{1}$ Abdul Rahman Omar, ${ }^{3}$ Boon Kee Beh and ${ }^{4}$ Huynh Ky \\ ${ }^{1}$ Institute of Bioscience, \\ ${ }^{2}$ Deptament of Cell and Molecular Biology, \\ ${ }^{3}$ Deptatment of Bioprocess Technology, \\ Faculty of Biotechnology and Biomolecular Sciences, \\ Universiti Putra Malaysia, 43400, Serdang, Selangor, Malaysia \\ ${ }^{4}$ Department of Agriculture Genetics and Breeding, \\ College of Agriculture and Applied Biology, Cantho University, Cantho City, Vietnam
}

\begin{abstract}
Problem statement: Numerous plants or remedies that are traditionally used for various diseases had been claimed to maintain general good health, particularly the immune system. With the advanced understanding on immunology and ethnopharmacology, study on the interaction of this herb with the immune system is critical to understand the safety and its efficacy as a potent immunomodulatory agent. Approach: Selecting proper immune cells from a suitable immune organ allowed for the understanding on the mode of immunomodulation. Lymphocytes isolated from mammalian thymus, spleen and bone marrow represented great candidates for this immunomodulatory study. Results: A number of herbal extracts including that of Rhaphidophora korthalsii and compounds isolated from this plant, namely lectin and zerumbone, had been identified as potent immunostimulators. Conclusion/Recommendations: Future studies are needed to elucidate the mechanism underlaying activites of these immunomodulatory agents.
\end{abstract}

Key words: Immunomodulation, PBMC, spleen, mitogen

\section{INTRODUCTION}

Immunomodulator is the substances that are capable of interacting with the immune system to upregulate or down-regulate specific aspect of the host response (Stanilove et al., 2005; Utoh-Nedosa et al., 2009). It is also known as biologic response modifier or immunoregulator which is function as drug leading predominantly to a non-specific stimulation of immunological defense mechanisms (Tzianabos, 2000). Immunomodulators may include some bacterial product, lymphokines and plant derived substances. The effects of immunomodulator can be classified into three which are stimulation, suppression and restoration of the immune system. Unlike vaccine, most of immunomodulator agents are not real antigens but antigenomimetics or so called mitogens. Due to their actions as a non-specific and nonantigens properties, they do not stimulate the development of memory lymphocytes. Thus the effect of immunomodulator agents towards specific immune system will be reduced after a short of period of time (Wagner, 1999).

Immunomodulators are used in clinical practice to stimulate and normalize an immune system activity. Most of the immunomodulator agents play their role in maintaining the immune system by increasing $\mathrm{T}$ cell immunity, decreasing or blocking the suppressor activity, stimulating the Natural Killer cells (NK cells) and interferon production as well as inducing specific cytokine production by activated target cells (Gabius, 2003; Stanilove et al., 2005; Lam et al., 2010). Nowadays, the application of imunomodulators is the practice of modern method for the correction of immunodeficiencies. According to Ganju et al. (2003), immunomodulation using medicinal plants can provide an alternative to conventional chemotherapy for a variety of diseases particularly when host defense mechanism has to be activated under the conditions of

Corresponding Author: Swee Keong Yeap, Institute of Bioscience, Universiti Putra Malaysia, 43400, Serdang, Selangor Malaysia Tel: +60389467471 Fax:+60389467510 
impaired immune response or when a selective immunosuppression is desired in situation like autoimmune disorders. The immuno-corrective properties of immunomodulators also can be successfully applied in the treatment of oncological diseases.

According to Wagner (1999), immunomodulators might be effective for the prophylaxis of metastases after removal of the primary tumor. It is also essential to facilitate the targeting and the recognition of diseased cells by immuno-competent cells. The immunocompetent cells play a principle role in the processes of eliminating tumors cells. These cells can be directed specifically towards the selected type of tumor cell or used in order to improve the immune resistance of the whole organism. Recently, the fundamental field of immunomodulator has involved in many medical areas such as treatment of organ rejection after transplantation, recovery from infectious diseases, primary immunodeficiencies and to stabilize the immune system of HIV positive patients.

Due to broad application of its action, immunomodulators are becoming very popular in the worldwide natural health industry as people start to realize the importance of a healthy immune system. However, selection of a proper target cells and markers are utmost important to evaluate the immunostimulatory effect of that particular substance.

Immune system: The immune system is the crucial body system which helps to protect the body against a wide variety of pathogens (Froy et al., 2007). Each structure of the immune system has a relatively fixed architecture of specialized organs, compound of lymphoid tissues, cells and chemicals. It has the ability to respond to antigen such as microbe or various macromolecules that is recognized as non-self or antigen. The success of this system in defending the body relies on an incredibly elaborate and dynamic regulatory communication networks, that involves multiple and functionally differing cell types which provide a large variety of defend mechanisms. The outcome is a sensitive system of check and balances that produces an immune response that is prompt, appropriate, effective and self-limiting (Becker, 2006; Zane, 2001).

Type of immune system: The human immune system has two defend system which can be divided into innate (or natural) immunity and adaptive (or acquired) immunity (Aagaard-Tillery et al., 2006). Natural or innate immunity is the body's first defense mechanisms against a foreign antigen. This mechanism do not required specific recognition of an antigen by the immune system (Vollmar, 2005). However, in situation in which the antigen escapes this natural protective mechanism and invades the host, another set of antigen specific and powerful defense mechanism are triggered due to "memory" of the cells. These mechanisms are known as adaptive (or acquired) immunity (Becker, 2006; Zane, 2001).

The acquired immunity can be subdivided into humoral immunity and cell mediated immunity which involved the reaction of lymphocytes. In the humoral immunity, it involves the secretion of antibodies which is B-lymphocytes that bind the antigen or enhances phagocytosis through opsonization to remove the stimulating antigen. Thus, it main mechanism in the body is to remove and neutralize the toxic. In contrast, the cell mediated immunity is mediated by the cytolytic $\mathrm{T}$ lymphocyte which can specifically recognize and activate the macrophages or kill the infected cells directly (Parslow, 2001). Both B and T lymphocytes are responsible in defending the immune system against infectious pathogen.

Organ and cells of the immune system: The immune system consists of cells and their secretory products, various lymphoid tissues and organ where these components are recognized and localized (Zane, 2001). The main components of the immune system are lymphoid tissue which divided into primary and secondary lymphoid tissue, cellular component such as lymphocytes and soluble components (mediator) like cytokines, antibodies and complement component. Two organs are designated as primary lymphoid tissues which are bone marrow and thymus whereas lymph nodes, spleen and scattered lymphoid tissue are designated as secondary lymphoid tissue. Thymus and spleen are group of primary and secondary lymphoid tissue, respectively whereas PBMC is a cellular component in the immune system which play an important role in the immune system and serve as a reservoir for foreign antigens.

Peripheral blood mononuclear cells: The human body is nourished by a dynamic circulatory system composed of cellular components of which have a relatively rapid turnover rate (Vlata et al., 2006). PBMC are classified as a fluid connective tissue, which can be termed as cells suspended in a fluid matrix functioning to connect the entire biological system at the physiological level. Blood cells also involve in the first line of the immune defense system, using an arsenal of neutrophils, eosinophils, basophils, B cells, T cells and monocytes to defend against foreign substances, injury and provide a protective barrier between the external and internal (Liew et al., 2006). These peripheral blood 
mononuclear cells play crucial role in the immune defense during the pathological conditions by stimulating the process of activation, cell division and differentiation to generate a large pool of activated effector T-cells which react to the antigen (Khanduja et al., 2006; Winkler et al., 2005).

Thymus: Thymus is a primary lymphoid tissue known as a dedicated organ for $\mathrm{T}$ cell development $(\mathrm{Wu}$, 2006). The thymus gland is a bilobeb structure, located in the thorax. Each lobe contains lymphoid cells (thymocytes) that form a tightly packed outer cortex and an inner medulla. The cortex contains the immature and proliferating cells, while the medulla contains of the more mature cells, indicating the existence of a maturation gradient from the cortex to medulla (Zane, 2001; Wu, 2006). During development, $\mathrm{T}$ cell progenitor originating from bone marrow migrates into the thymic epithelium. These progenitors are released in waves from bone marrow into the blood stream and then imported periodically into the thymus. The thymus provides a unique microenvironment where thymocytes proliferate and differentiate, passing through series of discrete phenotypic stages that can be identified by distinctive patterns of expression of various cell surface proteins (Godfrey and Zlotnik, 1993). The major function of the thymus is in the maturation and selection of an antigen specific T-lymphocytes from marrow derived precursor cells (Anderson et al., 1996). During the maturation process, the T-lymphocytes acquire surface receptors such as $\mathrm{T}$ cell receptors (Tcr) which is important in antigen recognition and the $\mathrm{T}$ cell activation process as well as in the identification of the cell's phenotype (Alvarez et al., 2006; Zane, 2001).

The thymus involutes (diminishes in size) with age, with only medullary remnants remaining. This involution of the thymic lymphoepithelial component is one of the most prominent features of ageing in the immune system. Based on study in animal and human, it is generally accepted that the volume of true thymic tissue attains maximum size at puberty, after that, it decreases gradually (Shanker, 2004). Therefore, with ageing, the thymic tissue weakens as a source of naïve T lymphocytes (Romanyukha and Yashin, 2003). The reduced $\mathrm{T}$ cell output, together with an increase in apoptosis of naïve T-cells limits the ability of aged individuals to respond to newly encountered antigens (Leposavic et al., 2006). The markedly reduced size of the naïve T-cell subpopulation together with an increased number of memory cells in the periphery, is a clear-cut characteristic of ageing in the immune cells (Romanyukha and Yashin, 2003). However, recently, Mocchegiani et al. (2006) reported that certain nutrition might effects thymic physiology. Studies on animals have shown that oral zinc supplement in aged mice induced thymus re-growth couple with an increase in the production of thymic hormone. As a result, this study suggested that dietary zinc supplement during the whole life-span might prevent the thymic involution during ageing processes.

Spleen: The spleen is the largest lymphoid organ in the body (Fedeler and Blatteis, 2006). It is a secondary lymphoid tissue and located in the left upper quadrant of the abdomen. It contains two compartments which are white pulp and red pulp with a marginal zone in between. The red pulp is composed of blood-filled vascular sinusoids while the white pulp is lymphoid tissue consisting mainly of lymphocytes surrounding the arteries. In the marginal zone it composes mainly B cells and macrophages (Parslow, 2001; Abbas et al., 2000). In this region also, the bloodstream passes through an open system of reticular cells and fibers in which various myeloid lymphoid cells are located. The $\mathrm{T}$ cells in the spleen are located in the periarteriolar lymphoid sheath. Macrophages in the marginal zone are well equipped to recognize pathogen and filter the blood by virtue of unique combination of pattern recognition receptors. They interact with a specific set of B cells that can be found only in a marginal zone and that are able to react rapidly to bacterial antigens in particular. In fact, around half of total body blood volume will pass through the spleen to filter the pathogen by using the sophisticated macrophages filtration system (Engwerda et al., 2005; Butcher, 2005).

In addition, spleen is also known to play several functions in the immune system. It plays an important role in defense against blood-borne pathogen because it consists of lymphocytes, dendritic cells, natural killer cells, red blood cells and macrophages. Besides to capturing antigens from the blood that passes through the spleen, migratory macrophages and dendritics cells bring antigens to the spleen via the bloodstream. This event will initiate an immune response by producing large amounts of antibody. Spleen also acts as reservoir area for blood when blood is needed in an emergency such as hemorrhage. In this situation the muscles in the spleen contract, forcing the stored blood out and back into general circulation. Spleen also destroys and wornout old blood cells as well as it plays an important role in red blood cell production (erythropoiesis) before birth (Parslow, 2001; Abbas et al., 2000; Portillo et al., 2004; Fedeler and Blatteis, 2006).

The capability of spleen possessing its role in the immune system linked intimately with the diet. 
Previously, Jeffery et al. (1997) proved that spleen lymphocytes proliferation was enhanced by palmitic acid rich diet which a group of saturated fatty acid found abundantly in palm oil. This result suggested that low fat diet can boost up the immune system. Subsequently, more recently, Field and his groups found that supplementing diet with additional folate significantly improved the distribution of $\mathrm{T}$ cells, increased mitogen responses and corrected most of the aberrant cytokine productions in the spleen (Field et al., 2006). Therefore, both results suggested that nutrition plays a crucial role in enhancing the immune system particularly in maintaining spleen health.

Lymphocytes: The lymphocytes are a class of leukocytes normally present in blood (Ndejembi et al., 2007). Their primary function is to survey the body and recognize any foreign material that may indicate the presence of virus, bacteria, parasites or tumor cells (Ndejembi et al., 2007; Victor, 2007). Lymphocytes can be grouped into different classes depending on their functions. The classes of lymphocytes are Blymphocytes, T-lymphocytes and Natural Killer cells (NK cells). The relative proportion of $\mathrm{T}$ and $\mathrm{B}$ cells in peripheral blood accounts for about 75 and $10 \%$ respectively, while the remaining $15 \%$ are NK cells (Cerqueira et al., 2004). All of them can be distinguished from one another and from other leukocytes on the basis of surface marker (Zane, 2001).

Classification of lymphocytes on the basis of surface marker makes use of two important classes of the characteristic which include the Cluster Designation (CD) and the nature of antigen recognition receptor expressed (Parslow, 2001). An important differential feature in antigen recognition by these two lymphocyte population is that $\mathrm{B}$ cell recognize native antigen configuration and require helper $\mathrm{T}$ cell (CD4+) participation in order for immune response to occur, whereas $\mathrm{T}$ cell $(\mathrm{CD} 8+$ and $\mathrm{CD} 4+)$ recognized only a "processed" antigen and in the context of self-MHC molecule (Parslow, 2001).

B-lymphocytes or the B cells are derived and developed from adult bone marrow and fetal liver. For adult mammals, the $\mathrm{B}$ cells are produce in the bone marrow and circulate in the blood stream in immature form. The selected phenotype markers which help to differentiate B lymphocytes from others are Fc receptors, class II MHC, CD19 and CD 21. B cells are responsible to produce antibodies (or immunoglobulin) which can bind specific with antigen in humoral immunity (Sen, 2006).

In contrast, the precursors of $\mathrm{T}$ lymphocytes originate in the bone marrow and mature in thymus. It is responsible for cell mediated immunity and can work with B cell in the humoral immune response. There are two types of T cell: Helper T lymphocyte (with CD3+, CD4+ and CD8- marker on the cell surface) and Cytolytic T lymphocytes (with CD3+, CD4- and CD8+ marker on the cell surface) and each of them carry different functions. The helper $\mathrm{T}$ cells are responsible for macrophage activation and stimulation of $\mathrm{B}$ cell growth and differentiation while Cytolytic $T$ lymphocytes are responsible for killing of virusinfected cells, tumor cells and allograft rejection after transplantation. Both the mature $\mathrm{B}$ and $\mathrm{T}$ lymphocytes will enter into the peripheral lymphoid organs such as lymph nodes, spleen, mucosal and cutaneous lymphoid tissues (Abbas et al., 2000).

The natural killer cells (NK cells) are a third population of lymphocytes. They express the CD2 marker, the $\mathrm{Fc}$ receptor for IgG molecule (CD16), the IL-2 receptor and elaborate Tissue Necrosis Factor (TNF). These cells are neither $\mathrm{T}$ nor B lymphocytes because their lack both the immunoglobulin (Ig) receptors normally present on a B lymphocytes surface and the specific T Cell Receptors (TCR) (Vivier, 2006). It functions as the non-specific killer toward the virusinfected cells and tumor cells (Morretta and Morretta, 2004; Eales, 2003).

Plant mitogens: One of the most important sources of immunomodulator which are being explored extensively currently is come from plants derived substances. There are several plants have been recognized to have mitogenic effect on the immune cells. For examples, Rhaphidophora korthalsii was found to stimulate immune cell proliferation, cytokines expression and natural killer cell cytotoxicity in vitro and in vivo (Yeap et al., 2007; 2011a; 2011b). On the other, Elephantopus scaber and Vernonia amygdalina were found to be the major ingredient in a traditional herbal formula, which carries the immunomodulatory effect (Ho et al., 2009; Yeap et al., 2010; Hertiani et al., 2010). A variety of substances have been discovered that bind to the surface of lymphocytes, thus stimulating them to undergo mitosis (Lao et al., 2001).

An example of lymphocyte mitogens are lectins. Lectins are glycoproteins or carbohydrate-binding proteins that have the ability to bind specifically, selectively, free or conjugated saccharides in a reversible way by two or more binding sites (Maciel et al., 2004). Some lectins induced lymphocytes proliferation or modulated several immune functions by interaction with their carbohydrate recognized receptors. One of the most dramatic effects of interaction of lections with the lymphocytes is their 
mitogenecity through triggering of quiescent, non dividing lymphocytes into a state of growth and proliferation (Bains et al., 2005). However, not all lymphocytes respond equally to all lectins (Lao et al., 2001). More recently, plant lectins are widely used in laboratory trial as stimuli for in vitro assessment of immune cells behavior and activity (Stanilove et al., 2005). The first plant lectin discovered was PHA, lectin isolated from red kidney bean (Phaseolus vulgaris) by Nowell (Bains et al., 2005). PHA has been identified to stimulate blastogenesis of T lymphocytes by interaction with CD2 to stimulate the production of IL-2 and IFN$\gamma$. This lectin primarily stimulates $\mathrm{T}$ cell proliferation, although it has a slight effect on B cells. The discovery of lectin-mediated mitogenesis led to the detection of many other mitogenic lectins, such as concanavalin A (Con A) and Pokeween Mitogen (PWM). Con A isolated from jack bean (Canavalia ensiformis) was found to bind specifically to alpha-D-glucopyranosides and alpha-D-mannosepyranosides. It has strong mitogenic effects on $\mathrm{T}$ cells but not on B cells. The lectin from phytollaca Americana, Pokeweed Mitogen (Pwm), has mitogenic activity on both $\mathrm{T}$ and $\mathrm{B}$ lymphocytes and induces various types of cytokines including type 1 cytokines (IL-2 and IFN- $\gamma$ ), type 2 cytokine (IL-10) and monokines (IL-6 and TNF- $\alpha$ ). Nevertheless, the specific receptor that couple with PWM is currently unidentified (Stanilove et al., 2005).

Besides lectin, other plant secondary metabolites including zerumbone (isolated from ginger), damnacanthal (isolated from noni) have also been proved to carry immunostimulatory effect via the examination of immunoproliferation, cell cycle alteration and anticancer cytokines (IL-2 and IL-12) expression (Keong et al., 2010, Alitheen et al., 2010). Upregulation of these cytokines has been reported to be apotential adjuvants in cancer immunotherapy (Capitini et al., 2009).

\section{CONCLUSION}

Immunomodulator especially immunostimulator carries number of potential benefit in maintaining strong immune system especially for the cancer patient who always associated with poor immunity while undergoing chemotherapy (Abdulamir et al., 2008; Wadekar et al., 2009). Herbs or plants which have been widely used in ethnopharmacology are the great source of immunomodulator. However, this bioactivity requires scientific proved to confirm the safety and effective dosage of that particular herb. Selecting the appropriate immune cells and specific immune organ as a study target for immunomodulation research allow the understanding of the interaction of that particular substances with the specific immune cells.

\section{REFERENCES}

Aagaard-Tillery, K.M., R. Silver and J. Dalton, 2006. Immunology of normal pregnancy. Semin Fetal Neonatal Med., 11: 279-295. PMID: 16784908

Abbas, A.K., A.H. Lichtman and J.S. Pober, 2000. Cellular and Molecular Immunology. 4th Edn., Saunders, Philadelphia, ISBN-10: 0721682332, pp: 553.

Abdulamir, A.S., R.R. Hafidh, N. Abdulmuhaimen, F. Abubaker and K.A. Abbas, 2008. Better Understanding of the Immunosuppressive link between the lymphocytic immune cells and the decreased cell mediated immunity in head and neck cancer patients. Am. J. Immunol., 4: 26-32. DOI: 10.3844/ajisp.2008.26.32

Alitheen, N.B., A.A. Manaf, S.K. Yeap, M. Shuhaimi and L. Nordin et al., 2010. Immunomodulatory effects of damnacanthal isolated from roots of Morinda Elliptica. Pharm Biol., 48: 446-452. PMID: 20645725

Alvarez, G., R. Lascurain, P. Hernandez-Cruz and D. Tetaert and P. Degand et al., 2006. Differential Oglycosylation in cortical and medullary thymocytes. Biochem. Biophys. Acta, 1760: 12351240. PMID: 16762509

Anderson, G., N.C. Moore, J.J. Owen and E.J. Jenjinson, 1996. Cellular interactions in thymocyte development. Annu Rev. Immunol., 14: 73-99. PMID: 8717508

Bains, J.S., J. Singh, S.S. Kamboj, K.K. Nijjar and J.N. Agrewala et al., 2005. Mitogenic and antiproliferative activity of a lectin from the tubers of Voodoo lily (Sauromatum venosum). Biochim. Biophys Acta., 1723: 163-174. PMID: 15788150

Butcher, G.A., 2005. The role of the spleen and immunization against malaria. Trends Parasitol., 21: 356-357. PMID: 15964781

Becker, K., 2006. Innate and adaptive immune responses in CNS disease. Clin. Neurosci. Res., 6: 227-236. DOI: 10.1016/j.cnr.2006.09.003

Capitini, C.M., T.J. Fry and C.L. Mackall, 2009. Cytokines as adjuvants for vaccine and cellular therapies for cancer. Am. J. Immunol., 5: 65-83. DOI: 10.3844/ajisp.2009.65.83

Cerqueira, F., A. Cordeiro-Da-Silva, C. GasparMarques, F. Simoes and M.M.M. Pinto et al., 2004. Effect of abietane diterpenes from Plectranthus grandidentatus on $\mathrm{T}$ - and $\mathrm{B}-$ lymphocyte proliferation. Bioorg. Med. Chem., 12: 217-223. PMID: 14697786 
Engwerda, C.R., L. Beattie and F.H. Amante, 2005. The importance of the spleen in malaria. Trends Parasitol., 21: 75-80. PMID: 15664530

Eales, L.J., 2003 Immunology for Life Scientists. 2nd Edn., John Wiley and Son, Chichester, ISBN: 0470845244 pp: 337.

Fedeler, C. and C.M. Blatteis, 2006. The role of the spleen in the febrile response induced by endotoxin in guinea pigs. J. Therm Biol., 31: 220-228. DOI: 10.1016/j.jtherbio.2005.11.024

Field, C.J., A.V. Aerde, K.L. Drajer, S. Goruk and T. Basu, 2006. Dietary folate improves age-related decreases in lymphocyte function. $\mathrm{J}$ Nutr. Biochem., 17: 37-44. PMID: 16098728

Froy, O., A. Hananel, N. Chapnik and Z. Madar, 2007. Differential effect of insulin treatment on decreased levels of beta-defensins and Toll-like receptors in diabetic rats. Mol. Immunol., 44: 796802. PMID: 16740310

Gabius, H.J., 2003. Probing the cons and pros of lectininduced immunomodulation: Case studies for the mistletoe lectin and galectin-1. Biochemie, 83: 659-666. PMID: 11522395

Ganju, L., D. Karan, S. Chanda, K.K. Srivastava and R.C. Sawhney et al., 2003. Immunomodulatory effects of agents of plant origin. Biomed. Pharmacother., 57: 296-300. DOI:10.1016/S07533322(03)00095-7 PMID: 14499177

Godfrey, D.I. and A. Zlotnik, 1993. Control points in early T-cell development. Immunol. Today., 14: 547-553. PMID: 7903854

Hertiani, T., E. Sasmito, Sumardi and M. Ulfah, 2010. Preliminary Study on immunomodulatory effect of sarang-semut tubers Myrmecodia tuberosa and Myrmecodia pendens. OnLine J. Biol. Sci., 10: 136-141. DOI: 10.3844/ojbsci.2010.136.141

Ho, W.Y., H. Ky, S.K. Yeap, A.R. Raha and A.R. Omar et al., 2009. Traditional practice, bioactivities and commercialization potential of Elephantopus scaber Linn. J. Med. Plant Res., 3: 1212-1221.

Jeffery, N.M., P. Sanderson, E.A. Newsholme and P.C. Calder, 1997. Effects of varying the type of saturated fatty acid in the rat diet upon serum lipid levels and spleen lymphocyte functions. Biochim. Biophys. Act., 1345: 223-236. PMID: 9150243

Khanduja, K.L., P.K. Avti, S. Kumar, N. Mittal and K.K. Sohi et al., 2006. Anti-apoptotic activity of caffeic acid, ellagic acid and ferulic acid in normal human peripheral blood mononuclear cells: A Bcl2 independent mechanism. Biochim. Biophys. Acta., 1760: 283-289. PMID: 16459021
Keong, Y.S., N.B. Alitheen, S. Mustafa, S.A. Aziz and M.A. Rahman et al., 2010. Immunomodulatory effects of zerumbone isolated from roots of Zingiber zerumbet. Pak. J. Pharm. Sci., 23: 75-82. PMID: 20067871

Lam, H.Y., S.K. Yeap, N.B. Alitheen, W.Y. Ho and A.R. Omar et al., 2010. Understand the role of natural killer. Am. J. Immunol., 6: 54-61. DOI: 10.3844/ajisp.2010.54.61

Lao, C.C., T.L. Lin and C.C. Wu, 2001. Factors affecting mitogenic response of turkey lymphocytes. Acta Vet. Brno., 70: 433-442.

Leposavic, G., V. Pesic, D. Kosec, K. Rodojevic and N. Arsenovic-Ranin et al., 2006. Age-associated changes in CD90 expression on thymocytes and in TCR-dependent stages of thymocyte maturation in male rats. Exp. Gerontol., 41: 574-589. PMID: 16632291

Liew, C.C., J. Ma, H.C. Tang, R. Zheng and A.A. Dempsey, 2006. The peripheral blood transcriptome dynamically reflects system wide biology: A potential diagnostic tool. J. Lab. Clin. Med., 147: 126-132. PMID: 16503242

Maciel, E.V., V.S. Araujo-Filho, M. Nakazawa, Y.M. Gomes and L.C. Coelho et al., 2004. Mitogenic activity of Cratylia mollis lectin on human lymphocytes. Biologicals, 32: 57-60. PMID: 15026026

Mocchegiani, E., L. Santarelli, L. Costarelli, C. Cipriano and E. Muti et al., 2006. Plasticity of neuroendocrine-thymus interactions during ontogeng and ageing: Role of zinc and arginine. Ageing. Res. Rev., 5: 281-309. PMID: 16904953

Morretta, L. and A. Morretta, 2004. Unravelling natural killer cell function: Triggering and inhibitory human NK receptors. EMBO J., 23: 255-259. PMID: 14685277

Ndejembi, M.P., A.L. Tang and D.L.Farber, 2007. Reshaping the past: Strategies for modulating Tcell memory immune responses. Clin. Immunol., 122: 1-12. PMID: 16916619

Portillo, H.A.D., M. Lanzer, S. Rodriguez-Malaga, F. Zavala and C. Fernandez-Becerra, 2004. Variant genes and the spleen in Plasmodium vivax malaria. Int. J. Parasitol., 34: 1547-1554. PMID: 15582531

Parslow, T.G., 2001. Medical Immunology. 10th Edn., Lange Medical Books/McGraw-Hill Medical Publishing Division, New York, ISBN: 0838563007, pp: 814.

Romanyukha, A.A. and A.I. Yashin, 2003. Age related changes in population of peripheral $\mathrm{T}$ cells: Towards a model of immunosenescence. Mech. Ageing. Dev., 124: 433-443. PMID: 12714250 
Sen, R., 2006. Control of B lymphocyte apoptosis by the transcription factor NF-қB. Immunity, 25: 871883. PMID: 17174931

Shanker, A., 2004. Is thymus redundant after adulthood. Immunol. Lett., 91: 79-86. PMID: 15019273

Stanilove, S.A., Z.G. Dobreva, E.S. Slavov and L.D. Mitera, 2005. C3 binding glycoprotein from Cuscuta Europea induced different cytokine profiles from human PBMC compared to other plant and bacterial immunomodulators. Int. Immunopharmacol, 5: 723-734. PMID: 15710341

Tzianabos, A.O., 2000. Polysaccharide immunomodulators as therapeutic agents: structural aspects and biologic function. Clin. Microbiol. Rev., 13: 523-533. PMID: 11023954

Utoh-Nedosa, A.U., P.A. Akah, T.C. Okoye and C.O. Okoli, 2009. Evaluation of the toxic effects of dihydroartemisinin on the vital organs of wistar albino rats. Am. J. Pharmacol. Toxicol., 4: 169173. DOI: 10.3844/ajptsp.2009.169.173

Victor, H.E., 2007. The contributions of mass spectrometry to understanding of immune recognition by $\mathrm{T}$ lymphocytes. Int. J. Mass. Spectrom., 259: 32-39. PMID: 18167512.

Vollmar, A.M., 2005. The role of atrial natriuretic peptide in the immune system. Peptides, 26: 10861094. PMID: 15911076

Vivier, E., 2006. What is natural in natural killer cells? Immunol. Lett., 107: 1-7. PMID: 16930725

Vlata, Z., F. Porichis, G. Tzanakakis, A. Tsatsakis and E. Krambovitis, 2006. A study of zearalenone cytotoxicity on human peripheral blood mononuclear cells. Toxicol. Lett., 165: 274-281. PMID: 16797886

Wadekar, K., S. Pandey, P. Jain, V.C. Roy and A. Asthana et al., 2009. Frequency of P/S(XX)P duplication and FRFE, absence of LYP in P6Gag of Indian human immunodeficiency virus-1 subtype C isolates. Am. Med. J., 1: 140-147. DOI: 10.3844/amjsp.2009.140.147
Wagner, H., 1999. Immunomodulatory Agents from Plants. 1st Edn., Birkhauser, Germany, ISBN: 3764358483, pp: 365.

Winkler, C., B. Wirleitner and K. Schroecksnadel, 2005. In vitro effects of beet root juice on stimulated and unstimulated peripheral blood mononuclear cells. Am. J. Biochem. Biotechnol., 1: 180-185. DOI: 10.3844/ajbbsp.2005.180.185

Wu, L., 2006. T lineage progenitors: the earliest steps en route to $\mathrm{T}$ lymphocytes. Curr. Opin. Immunol., 18: 121-126. PMID: 16459068

Yeap, S.K., N.B. Alitheen, A.M. Ali, A.R. Omar and A.R. Raha et al., 2007. Effect of Rhaphidophora korthalsii methanol extract on human Peripheral Blood Mononuclear Cell (PBMC) proliferation and cytolytic activity toward HepG2. J. Ethnopharmacol., 114: 406-411. PMID: 17884317

Yeap, S.K., W.Y. Ho, B.K. Beh, W.S. Liang and H. Ky et al., 2010. Vernonia amygdalina, an ethnoveterinary and ethnomedical used green vegetable with multiple bio-activities. J. Med. Plant Res., 4: 2787-2812.

Yeap, S.K., A.R. Omar, W.Y. Ho, B.K. Beh and A.M. Ali et al., 2011a. Immunomodulatory effect of Rhaphidophora korthalsii on mice splenocyte, thymocyte and bone marrow cell proliferation and cytokine expression. Afr. J. Biotechnol., 10: 10744-10751.

Yeap, S.K., N.B.M. Alitheen, W.Y. Ho, A.R. Omar and A.M. Ali et al., 2011b. Immunomodulatory role of Rhaphidophora korthalsii methanol extract on human peripheral blood mononuclear cell proliferation, cytokine secretion and cytolytic activity. J. Med. Plant Res., 5: 958-965.

Zane, H.D., 2001. Immunology: Theoretical and Practical Concepts in Laboratory Medicine. 1st Edn., W.B. Saunders Company, United State, pp: 366. 